\title{
A Corpus-based Comparison of Terms of Dress and Personal Adornment in Hong Lou Meng and Its English Versions
}

\author{
Dan ZHOU \\ School of Foreign Languages, Wuhan Textile University, Wuhan, 430200, China \\ email: Zhoudan@wtu.edu.cn
}

Keywords: Hong Lou Meng; English Version; Corpus-based; Terms of Dress and Personal Adornment

\begin{abstract}
Based on previous studies of dress and personal adornment on HLM, the study aims to define and classify terms of dress and personal adornment (to be abbreviated as TDPA hereinafter) in HLM. With the aid of the HLM Chinese-English parallel corpus, the study sets out to search TDPA in HLM and their renditions in three English translations, taking advantage of a wordlist of terms of dress and a wordlist of terms of personal adornment. The implications of this descriptive and comparative study may lie in summarizing the rules of translating TDPA, shedding light on the translation of TDPA in other Chinese classical works, and offering help in future translation teaching and translation practice.
\end{abstract}

\section{Introduction}

Due to its unique artistic charm, HLM has already set off a great mass fervor in studying it at home. With translations into eighteen languages, in fifty-three versions, abridged and complete (Zhu, 1997:303) and nine English versions (Chen \& Jiang, 2003:46) up to date, the translation of HLM has become a distinctive and splendid landscape in the history of translating Chinese literary works. [1] Among the nine English versions of HLM, the earliest unabridged version is $\mathrm{H}$. Bencraft Joly's (to be abbreviated as "Joly" hereafter) two-volume translation of HLM, under the title of Hung Lou Meng or The Dream of the Red Chamber, A Chinese Novel, which is published in Hong Kong in 1892-93. His work "represents the highest achievement in the English translation of HLM in the nineteenth century" ( $\mathrm{Hu}, 2005: 130)$. He failed to present the English-reading audience a full version of the HLM story, so that readers are unable to appreciate the complete story of HLM faithfully and fluently translated by him. [2] There are also two complete and conspicuous English versions, one is the 120-chapter version translated by a Chinese scholar and translator Yang Hsienyi and his British wife Gladys Yang (both of whom are collectively abbreviated as "the Yangs" hereafter) from 1978 to 1980, with the translated name of "A Dream of Red Mansions". The other is the 120 chapters version translated by David Hawkes and John Minford (hereinafter referred to as "Hawkes') with the translated name of "The Story of the Stone". [3] The research is to explore the underlying reasons that make the translators adopt different translation strategies when translating TDPA in HLM. This study describes the characteristics and functions of the descriptions on TDPA in the one hundred and twenty chapters of HLM. Compares and contrasts the translation strategies and methods adopted by Hawkes, the Yangs and Joly for translating TDPA that occur in the first fifty-six chapters of HLM, and evaluates to what extent the three English versions represent the cultural values of TDPA in HLM. 


\section{Literature review}

Table 1 Articles on English translations of HLM

\begin{tabular}{|c|c|c|}
\hline Content & Articles & Percentage \\
\hline Poetry Translation & 12 & $24 \%$ \\
\hline Translation of Culture & 7 & $14 \%$ \\
\hline Character D iscourse Translation & 3 & $6 \%$ \\
\hline Book Title Translation & 3 & $6 \%$ \\
\hline History of $H L M$ Translations & 2 & $4 \%$ \\
\hline Chapter Title Translation & 2 & $4 \%$ \\
\hline Epigram and Proverb Translation & 2 & $4 \%$ \\
\hline Rhetorical Devices Translation & 1 & $2 \%$ \\
\hline Literary Character Translation & 1 & $2 \%$ \\
\hline Lantern Puzzle Translation & 1 & $2 \%$ \\
\hline Couplet Translation & 1 & $2 \%$ \\
\hline Personal Name Translation & 1 & $2 \%$ \\
\hline Others & 14 & $28 \%$ \\
\hline
\end{tabular}

Compared with the great wave of studies on HLM, the depth and width of studies on the English translations of HLM has yet to be improved. Apart from the above mentioned studies on the English translations of HLM from the year 1990 to 2013, there are also many articles on the translation studies of HLM published on some academic journals.

\section{Definitions for dress and personal adornment}

There have been some different opinions about the definition of “服饰 (fú shì, dress and personal adornment) " in the academic circles. In Ci Hai (1979:1513) and Modern Chinese Dictionary (2005:419) it is defined as "clothes and decoration". The above two definitions are too simple. Chinese Costume Dictionary (1996:1) defines it as: "clothing and jewelry, including crown, scarves, hair-style, clothes, trousers, footwear, adornment, etc..."Based on the above definitions, this paper defines the term“服饰 (fú shì, dress and personal adornment)”as: dress and personal adornment. Some scholars and researchers have also made studies on the renditions of TDPA in HLM. Shi (2012) and Feng (2014) focus on the translation strategies of TDPA by comparing some examples from the Yangs' and Hawkes' versions.

\section{Corpora and translation studies}

Through exemplifying its advantages and practices, it shows the implications and feasibility of making a corpus-based translation study of TDPA in HLM. In order to judge the translator's "capturing patterns of choice rather than individual choices" (Baker, 2000:246), the translation will be more persuasive. Nowadays, many large corpora are created based on the modern computer 
technology in order to study translation, and a large body of data can be macro-contrasted and quantitatively analyzed if aided by the corpus tools. With the continuous improvement of computer technology, corpus and corpus linguistics have developed rapidly and the large-scale corpora have been gradually created. Baker (1993) is the first one to advocate that corpus should be applied to explore the translation phenomena. [4] Toury (1995) insists that corpora will help find the features with regularity in translation quickly, thus finding two regulars in translation and advancing the standards of corpus design. Malmkjaer (1998) points out that parallel corpus studies can reveal characteristics of translated texts, compare the target language and source language and help to identify translation norms and to create machine translation programs and bilingual dictionaries. his study sets out to make a comparison and contrast of the renditions of TDPA in HLM among three versions (i.e. Hawkes' version, the Yangs' version, and Joly's version) in order to get more reliable and impartial conclusions.

\section{Data Analysis and Discussion}

\section{A. Features of the description on dress and personal adornment}

For the description of dress in HLM, there are more than thirty materials, such as 锻 (duàn, satin), 绫 (líng, damask silk), 棉 (mián, cotton), 纱 (shā, voile), 洋绉 (yáng zhòu, foreign crape), 羽纱 (yǔ shā, camlet), 猩猩毡 (xīng xīng zhān, felt), 哆罗呢 (duō luó ní, duoluo velvet), 银鼠皮 (yín shŭ pí, silver squirrel skin), 灰鼠皮 (hūi shŭ pí, grey squirrel skin), 貂皮 (diāo pí, marten skin), 海龙皮 (hăi lóng pí, otter skin). However, not only weavers, first class tailors and embroiderers but also those who do women's work have no idea what this gown is made of, therefore none of them will venture to undertake the job. So this peacock down gown must be extremely rare and valuable.

a. Colorfulness of dress

According to Chen, Gan, Tan and Wang (2007), who makes a study on the color of dress in HLM, there are mainly seven types of dress colors, namely red type. under this type there are nine sub-types: 大红 (dà hóng, dark red), 猩红 (xīng hóng, orangutan red), 银红 (yín hóng, silver red), 桃红 (táo hóng, peach red), 水红 (shuǐ hóng, water red), 海棠红 (hăi táng hóng, crab apple red), 红 (hóng, red), 石榴红 (shí líu hóng, megranate red) and 玉色红 (yù sè hóng, jade red).

b. Varieties of dress pattern

In HLM nine clothes patterns are described, namely: 蝴蝶 (hú dié, butterfly), 蟒 (măng, boa), 撒花 (sā huā, sprigged flower), 盘金 (pán jīn, silk embroidery), 弹墨 (tán mò, blacking), 刻丝 (kè sī, insetting silk), 团花 (tuán huā, group flower), 掐牙 (qiā yá, scalloped borders) and 镶边 (xiāng biān, side embroidery). There are a lot of descriptions on "boa" pattern in HLM. The formal dress of Jia Baoyu is a narrow-sleeved archer's jacket with "boa" patterns. For example, in Chapter eight of HLM when Jia Baoyu goes to visit Aunt Xue, he wears "a light yellow, archery-sleeved jacket, ornamented with rampant dragons, and lined with fur from the ribs of the silver fox" (Joly, 1892-1893 (Book I):91). 


\section{B. Description of TDPA in HLM}

Table 3 TDPA in HLM

\begin{tabular}{|c|c|c|c|c|c|c|c|c|c|}
\hline \multirow{2}{*}{\multicolumn{2}{|c|}{ TDPA }} & \multicolumn{2}{|c|}{$1-120$} & \multicolumn{2}{|c|}{$1-80$} & \multicolumn{2}{|c|}{$1-56$} & \multicolumn{2}{|c|}{$80-120$} \\
\hline & & type & token & type & token & type & token & type & token \\
\hline \multirow{5}{*}{ dress } & $\mathrm{UC}$ & 20 & 177 & 17 & 152 & 15 & 116 & 13 & 25 \\
\hline & $\mathrm{NC}$ & 4 & 79 & 4 & 70 & 3 & 29 & 2 & 9 \\
\hline & FW & 4 & 71 & 4 & 66 & 4 & 43 & 5 & 2 \\
\hline & $\mathrm{HG}$ & 8 & 43 & 8 & 40 & 5 & 26 & 1 & 4 \\
\hline & WW & 4 & 34 & 4 & 25 & 4 & 21 & 2 & 9 \\
\hline \multicolumn{2}{|c|}{ Total of dress } & 40 & 404 & 38 & 353 & 31 & 235 & 23 & 49 \\
\hline \multirow{6}{*}{ PA } & $\mathrm{H}^{1} \mathrm{~A}$ & 8 & 72 & 8 & 61 & 7 & 50 & 4 & 11 \\
\hline & $\mathrm{H}^{2} \mathrm{~A}$ & 1 & 8 & 1 & 8 & 1 & 8 & 0 & 0 \\
\hline & WA & 3 & 31 & 3 & 28 & 3 & 19 & 2 & 3 \\
\hline & E A & 2 & 6 & 2 & 6 & 1 & 2 & 0 & 0 \\
\hline & $\mathrm{NA}$ & 8 & 52 & 8 & 45 & 8 & 39 & 3 & 7 \\
\hline & BA & 5 & 63 & 4 & 56 & 5 & 37 & 4 & 7 \\
\hline \multicolumn{2}{|c|}{ Total of PA } & 27 & 232 & 26 & 204 & 25 & 155 & 13 & 28 \\
\hline \multicolumn{2}{|c|}{ Total of TDPA } & 67 & 636 & 64 & 557 & 56 & 390 & 36 & 77 \\
\hline
\end{tabular}

As we can see clearly in the following Table 3, in the one hundred and twenty chapters of HLM, there are 636 tokens and 67 types of dress and personal adornment in total, and among them the dress terms have 404 tokens and 40 types in all, and the terms of personal adornments have 232 tokens and 27 types in all.

\section{TDPA in 1-80 chapters and 80-120 chapters of HLM}

In the first eighty chapters of HLM, there are 557 tokens and 64 types of dress and personal adornment in all, and among them dress has 353 tokens and 38 types, personal adornments have 204 tokens and 26 types. In the last forty chapters of HLM, there are 77 tokens and 36 types of dress and personal adornment in all, and among them dress has 49 tokens and 23 types, personal adornments have 28 tokens and 13 types.

When translating terms of personal adornment, Joly and the Yangs prefer semantic approach to communicative approach, while Hawkes prefers communicative approach to semantic approach. [5] Except for semantic and communicative translation methods, Hawkes, the Yangs and Joly all use pronouns to render some terms of personal adornment, and they omit of them. In Hawkes', the Yangs and Joly' versions, there are no renditions for some terms of personal adornment in HLM.

\section{Conclusion}

Based on the previous studies on terms of dress and personal adornment in HLM, this study sets out to define and classify the terms of dress and personal adornment. With the aid of the HLM Chinese-English corpus parallel of sentence-to-sentence alignment and the corpus instruments as ParaConc, all the terms of dress and personal adornment in the HLM and their renditions in Hawkes', the Yangs' and Joly' versions are found out. By analyzing the English counterparts of terms of dress and personal adornment, it is found that the three translators' English renditions cannot be simply classified as productions that are either the result of a pure. This study suggests a cultural view on rendering terms that have high cultural connotations. As far as comparisons of the terms of dress and personal adornment in HLM and their English renditions, this analysis has shown that the HLM Chinese-English parallel corpus can provide the translation studies of dress and personal adornment in HLM with the visible, objective and inter-subjective testable results. 


\section{Acknowledgement}

In this paper, the research was sponsored by Project of Humanities and Social Science of Hubei Province (Project No. 2015Q099)

\section{References}

[1] Hartsuiker Robert J, Pickering Martin J, Veltkamp Eline. Is syntax separate or shared between languages? Cross-linguistic syntactic priming in Spanish-English bilinguals.[J]. Psychological Science, 2004, 15(6).

[2] Cao Bi-Yin. [Pondering the problems and development of English translation for traditional Chinese medicine].[J]. Zhongxiyi Jiehe Xuebao, 2006, 4(1).

[3] Murphy J F A. Communicating with patients when English is not their first language.[J]. Irish Medical Journal, 2006, 99(8).

[4] Jones Elaine G, Mallinson R Kevin, Phillips Linda et al.. Challenges in language, culture, and modality: translating English measures into American sign language.[J]. Nursing Research, 2006, $55(2)$.

[5] Qin Yao. Cultural Awareness in Dealing with the Color "Red"-With Reference *to the Translation of Hong Lou Meng[J]. Journal of Language Teaching and Research, 2010, 1(5). 